Frequency and Prognostic Significance of Abnormal Liver Function Tests in Patients With Cardiogenic Shock

\author{
Jäntti, Toni
}

2017-10-01

Jäntti , T , Tarvasmäki , T , Harjola , V-P , Parissis , J , Pulkki , K, Sionis , A , Silva-Cardoso

, J , Kober , L , Banaszewski , M , Spinar , J , Fuhrmann , V , Tolonen , J , Carubelli , V , diSomma , S , Mebazaa , A , Lassus , J \& CardShock Investigators 2017 , ' Frequency and Prognostic Significance of Abnormal Liver Function Tests in Patients With Cardiogenic Shock ', American Journal of Cardiology , vol. 120 , no. 7 , pp. 1090-1097 . https://doi.org/10.1016/j.amjcard.2017.0

http://hdl.handle.net/10138/298080

https://doi.org/10.1016/j.amjcard.2017.06.049

publishedVersion

Downloaded from Helda, University of Helsinki institutional repository.

This is an electronic reprint of the original article.

This reprint may differ from the original in pagination and typographic detail.

Please cite the original version. 


\title{
Frequency and Prognostic Significance of Abnormal Liver Function Tests in Patients With Cardiogenic Shock
}

\author{
Toni Jäntti, MD ${ }^{\mathrm{a}, *}$, Tuukka Tarvasmäki, $\mathrm{MD}^{\mathrm{b}}$, Veli-Pekka Harjola, MD ${ }^{\mathrm{b}}$, John Parissis, MD ${ }^{\mathrm{c}}$, \\ Kari Pulkki, MD ${ }^{\mathrm{d}}$, Alessandro Sionis, MD ${ }^{\mathrm{e}}$, Jose Silva-Cardoso, MD ${ }^{\mathrm{f}}$, Lars Køber, MD $^{\mathrm{g}}$, \\ Marek Banaszewski, MD ${ }^{\mathrm{h}}$, Jindrich Spinar, MD ${ }^{\mathrm{i}}$, Valentin Fuhrmann, MD ${ }^{\mathrm{j}}$, Jukka Tolonen, MD ${ }^{\mathrm{a}}$, \\ Valentina Carubelli, $\mathrm{MD}^{\mathrm{k}}$, Salvatore diSomma, $\mathrm{MD}^{1}$, Alexandre Mebazaa, $\mathrm{MD}^{\mathrm{m}, \mathrm{n}}$, and \\ Johan Lassus, $\mathrm{MD}^{\circ}$ for the CardShock investigators
}

\begin{abstract}
Cardiogenic shock (CS) is a cardiac emergency often leading to multiple organ failure and death. Assessing organ dysfunction and appropriate risk stratification are central for the optimal management of these patients. The purpose of this study was to assess the prevalence of abnormal liver function tests (LFTs), as well as early changes of LFTs and their impact on outcome in CS. We measured LFTs in 178 patients in CS from serial blood samples taken at 0 hours, 12 hours, and 24 hours. The associations of LFT abnormalities and their early changes with all-cause 90-day mortality were estimated using Fisher's exact test and Cox proportional hazards regression analysis. Baseline alanine aminotransferase (ALT) was abnormal in $\mathbf{5 8 \%}$ of the patients, more frequently in nonsurvivors. Abnormalities in other LFTs analyzed (alkaline phosphatase, gamma-glutamyl transferase, and total bilirubin) were not associated with short-term mortality. An increase in ALT of $>\mathbf{2 0 \%}$ within 24 hours $(\triangle \mathrm{ALT}>+20 \%)$ was observed in $24 \%$ of patients. $\triangle \mathrm{ALT}>+20 \%$ was associated with a more than 2-fold increase in mortality compared with those with stable or decreasing ALT (70\% and $28 \%, p<0.001)$. Multivariable regression analysis showed that $\triangle A L T>+20 \%$ was associated with increased 90-day mortality independent of other known risk factors. In conclusion, an increase in ALT in the initial phase was seen in 1/4 of patients in CS and was independently associated with 90-day mortality. This finding suggests that serial ALT measurements should be incorporated in the clinical assessment of patients in CS. () 2017 Elsevier Inc. All rights reserved. (Am J Cardiol 2017;120:1090-1097)
\end{abstract}

Abnormal liver function tests (LFTs) are a common finding in acute and chronic heart failure. Their association with worse outcomes has been well established for chronic heart failure, ${ }^{1,2}$ but their role in acute heart failure has attracted attention only recently. ${ }^{3-10}$ Despite some recent studies, the role of changes in LFTs during hospitalization for acute heart failure remains

${ }^{a}$ Internal Medicine, University of Helsinki and Department of Internal Medicine, Helsinki University Hospital, Helsinki, Finland; 'Emergency Medicine, University of Helsinki and Department of Emergency Medicine and Services, Helsinki University Hospital, Helsinki, Finland; ${ }^{\mathrm{H} H e a r t}$ Failure Clinic, Secondary Cardiology Department, Attikon University Hospital, Athens, Greece; ${ }^{\mathrm{d} D e p a r t m e n t}$ of Clinical Chemistry, University of Eastern Finland and Eastern Finland Laboratory Centre (ISLAB), Kuopio, Finland; ' Intensive Cardiac Care Unit, Cardiology Department, Hospital de la Santa Creu i Sant Pau, Biomedical Research Institute IIB-SantPau, Universidad Autónoma de Barcelona, Barcelona, Spain; ${ }^{\mathrm{f}}$ Department of Cardiology, CINTESIS, Porto Medical School, São João Hospital Center, University of Porto, Porto,

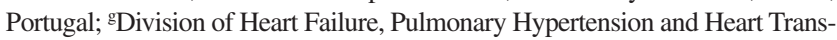
plantation, Rigshospitalet, Copenhagen University Hospital, Copenhagen, Denmark; 'Intensive Cardiac Therapy Clinic, Institute of Cardiology, Warsaw, Poland; 'Department of Internal Medicine and Cardiology, University Hospital Brno, Brno, Czech Republic; 'Department of Intensive Care Medicine, University Medical Center Hamburg-Eppendorf, Hamburg, Germany; ${ }^{\mathrm{k}}$ Division of Cardiology, Department of Medical and Surgical Specialties, Radiological controversial. $^{3-7}$ Cardiogenic shock (CS) is the most severe form of acute heart failure, characterized by severe hypoperfusion caused by cardiac dysfunction despite adequate filling pressures. ${ }^{11}$ Without prompt treatment, CS often leads into a spiral of multiple organ failure and systemic inflammatory response, eventually resulting in death. ${ }^{12}$ Although

Sciences, and Public Health, University and Civil Hospital of Brescia, Brescia, Italy; 'Department of Medical Sciences and Translational Medicine, Sant'Andrea Hospital, University of Rome Sapienza, Rome, Italy; ' INSERM U942, University Paris Diderot, Paris, France; ${ }^{n}$ Department of Anesthesia and Critical Care, Hôpital Lariboisière, APHP, Paris, France; and ${ }^{\circ}$ Cardiology, University of Helsinki and Department of Cardiology, Heart and Lung Center, Helsinki University Hospital, Helsinki, Finland. Manuscript received March 24, 2017; revised manuscript received and accepted June 29, 2017.

This study was supported by grants from the Finnish Foundation for Cardiovascular Research and Aarne Koskelo Foundation, Helsinki, Finland. Roche Diagnostics provided kits for the analysis of NT-proBNP and TnT. The funding sources had no role in the design and conduct of the study; collection, management, analysis, and interpretation of the data; preparation, review, or approval of the manuscript; or decision to submit the manuscript for publication.

See page 1096 for disclosure information.

*Corresponding author: Tel: +358 9 4711; fax: +358 947171488.

E-mail address: toni.jantti@ fimnet.fi (T. Jäntti). 
abnormal LFTs indicating hepatic impairment are a common finding in critically ill patients and have been shown to be associated with a worse prognosis, ${ }^{13-15}$ the prevalence and prognostic significance of ischemic liver injury, that is, hypoxic hepatitis, in CS has not been well studied. A recent study by Jung et $\mathrm{al}^{16}$ showed that hypoxic hepatitis, as defined by alanine aminotransferase (ALT) levels $>20$ times the upper limit of normal within 72 hours of shock, was associated with higher 30-day mortality. However, the effect of more modest early increases in transaminases as well as the role of other LFT abnormalities in CS remains unstudied. The purpose of this study was to assess the prevalence of abnormal LFTs, their changes, and impact on outcome in patients in CS.

\section{Methods}

The CardShock study (NCT01374867 at www.clinicaltrials .gov) is a European prospective, observational, multicenter and multinational study on CS. Patients were recruited between October 2010 and December 2012 from emergency departments, cardiac and intensive care units, as well as catheterization laboratories in 9 tertiary hospitals from 8 countries. The study enrolled consecutive patients aged older than 18 years within 6 hours from identification of CS (for details, see Harjola et $\mathrm{al}^{17}$ ). The inclusion criteria were (1) systolic blood pressure $<90 \mathrm{~mm} \mathrm{Hg}$ (after adequate fluid challenge) for 30 minutes, or need of vasopressor therapy to maintain systolic blood pressure $>90 \mathrm{~mm} \mathrm{Hg}$ and (2) signs of hypoperfusion (altered mental status, cold periphery, oliguria $<0.5 \mathrm{ml} / \mathrm{kg} / \mathrm{h}$ for the previous 6 hours, or blood lactate $>2 \mathrm{mmol} / \mathrm{L}$ ). Exclusion criteria were shock caused by ongoing hemodynamically significant arrhythmias or shock after cardiac or noncardiac surgery. The etiology of CS was determined by local investigators. Acute coronary syndrome etiology was defined as shock caused by myocardial infarction. Echocardiography was performed per protocol at study entry. Patients were treated according to local practice, and treatment and procedures were registered. Invasive hemodynamic monitoring was based on clinical evaluation and used at the discretion of the treating physician. Cardiac output was measured with the thermodilution method, using the average from 3 sequential measurements. Cardiac index was calculated by dividing the cardiac output by body surface area calculated from weight and height.

Blood sampling was performed at baseline (0 hours; $\mathrm{n}=178)$ and serially at 12 -hour intervals from baseline (12 hours, 24 hours; both +/-3 hours). Plasma samples were immediately frozen in aliquots and stored at $-80^{\circ} \mathrm{C}$. We analyzed creatinine, C-reactive protein, high-sensitivity troponin $\mathrm{T}$ (hsTnT), N-terminal prohormone of B-type natriuretic peptide, ALT, alkaline phosphatase, gamma-glutamyl transferase (GGT), and total bilirubin (Roche Diagnostics, Basel, Switzerland) at a central laboratory (ISLAB, Kuopio, Finland). These analyses were accredited by the Finnish Accreditation Service according to EN15189 and ISO17025. The cutoffs used to determine abnormal values for the LFTs were $35 \mathrm{U} / \mathrm{L}$ for ALT, $105 \mathrm{U} / \mathrm{L}$ for alkaline phosphatase, $60 \mathrm{U} / \mathrm{L}$ for GGT, and $25 \mu \mathrm{mol} / \mathrm{L}$ for bilirubin. Estimated glomerular filtration rate was calculated from creatinine values using the Chronic Kidney Disease Epidemiology Collaboration equation. ${ }^{18} \mathrm{Ar}-$ terial blood lactate was analyzed locally.
An increase in LFT values was defined as a rise by $>20 \%$ from the first measurement to the highest value within 24 hours from baseline. A cutoff of $>20 \%$ increase was chosen based on receiver operating characteristic curve analysis and has been used in a previous investigation on patients with acute heart failure. ${ }^{5}$ At least 2 separate LFT values within 24 hours $(0$, 12 , and 24 hours) were available for 156 of 178 patients. Patients with the highest LFT value in the normal range were considered to have no significant LFT increase. Sensitivity analyses were performed using different cut-off values for both the increase $(>+25 \%$ within 24 hours) and the highest level within 24 hours ( $>2$ times the upper limit of normal).

The primary end point was 90-day all-cause mortality. Vital status during follow-up was determined through direct contact with the patient or next of kin, or through population and hospital registries. Two patients were lost to follow-up. The study was approved by local ethics committees and conducted in accordance with the Declaration of Helsinki. Results are presented as numbers (n) and percentages (\%), means and standard deviations, or medians and interquartile ranges for variables with a skewed distribution. Between-group comparisons were performed using Student $t$ test or MannWhitney $U$ test, as appropriate. Differences in categorical variables were assessed by Fisher's exact test. For differences in Kaplan-Meier survival curves, the log-rank test was used. Cox proportional hazards model analysis was used to identify variables associated with 90-day mortality. In the multivariable models, adjustment was made for the variables included in the recently published CardShock risk score, ${ }^{17}$ that is, age, history of myocardial infarction or coronary bypass grafting, altered mental status at presentation, acute coronary syndrome etiology, left ventricular ejection fraction, lactate, and estimated glomerular filtration rate on admission. Log-minus-log plots were used to evaluate the adequacy of the proportional hazards assumption. Results from the regression analyses are presented as hazard ratios (HRs) with 95\% confidence intervals. To determine independent predictors of $\Delta \mathrm{ALT}>+20 \%$, baseline variables with a univariable $\mathrm{p}<0.1$ were entered into a multivariable logistic regression model. Stepwise forward and backward likelihood ratio test with significance $<0.05$ for inclusion and $>0.1$ for elimination was used to determine independent predictors with a $\mathrm{p}$ value of $<0.05$ in a multivariable logistic regression model. Data were analyzed using SPSS Statistics version 23 (IBM Corp, Armonk, NY).

\section{Results}

The study cohort comprised 178 patients in CS with all LFTs (ALT, alkaline phosphatase, GGT, and bilirubin) available at baseline. The mean age was 66 (12) years, and 74\% were men. On average, mean arterial pressure for all patients in the cohort was 57 (11) $\mathrm{mm} \mathrm{Hg}$. The main etiology of CS was acute coronary syndrome $(80 \%)$. The 90 -day allcause mortality was $42 \%$.

In the LFTs analyzed, ALT was the most frequently abnormal, as summarized in Table 1. Median ALT at baseline (ALT-0h) was $44 \mathrm{U} / \mathrm{L}$, and ALT-0h was above the upper limit of normal in $102(58 \%)$ patients. Abnormal values in other LFTs were less frequent and elevations were less prominent (Table 1). Higher baseline lactate levels $(2.4 \mathrm{mmol} / \mathrm{L} \mathrm{vs}$ 
Table 1

Distribution of abnormal liver function test values at different time points

\begin{tabular}{|c|c|c|c|c|c|c|}
\hline Variable & Number of patients & Survivors median (IQR) & Abnormal & Non-survivors median (IQR) & Abnormal & $\mathrm{p}$ value* \\
\hline \multicolumn{7}{|c|}{ Alanine aminotransferase (U/L) } \\
\hline 0 hours & 176 & $38(18-81)$ & $52(51 \%)$ & $56(25-121)$ & $50(68 \%)$ & 0.03 \\
\hline 12 hours & 152 & $33(15-70)$ & $45(49 \%)$ & $74(34-159)$ & $43(72 \%)$ & 0.007 \\
\hline 24 hours & 139 & $28(16-63)$ & $39(43 \%)$ & $61(29-130)$ & $34(71 \%)$ & 0.002 \\
\hline \multicolumn{7}{|c|}{ Alkaline phosphatase (U/L) } \\
\hline 0 hours & 176 & $60(47-78)$ & $14(14 \%)$ & $63(49-82)$ & $5(7 \%)$ & 0.22 \\
\hline 12 hours & 152 & $60(47-72)$ & $9(10 \%)$ & $57(46-70)$ & $4(7 \%)$ & 0.57 \\
\hline 24 hours & 139 & $57(43-71)$ & $6(7 \%)$ & $54(42-69)$ & $4(8 \%)$ & 0.74 \\
\hline \multicolumn{7}{|c|}{ Gamma-glutamyl transferase (U/L) } \\
\hline 0 hours & 176 & $57(34-106)$ & $47(46 \%)$ & $47(28-79)$ & $31(42 \%)$ & 0.35 \\
\hline 12 hours & 152 & $55(31-101)$ & $42(46 \%)$ & $46(32-81)$ & $22(37 \%)$ & 0.32 \\
\hline 24 hours & 139 & $52(31-99)$ & $36(40 \%)$ & $43(31-76)$ & $15(31 \%)$ & 0.36 \\
\hline \multicolumn{7}{|c|}{ Total bilirubin $(\mu \mathrm{mol} / \mathrm{L})$} \\
\hline 0 hours & 176 & $9.6(6.0-16.6)$ & $12(12 \%)$ & $9.4(5.6-15.4)$ & $9(12 \%)$ & 0.99 \\
\hline 12 hours & 152 & $9.9(6.8-15.7)$ & $10(11 \%)$ & $9.2(5.2-16.8)$ & $3(5 \%)$ & 0.25 \\
\hline 24 hours & 139 & $10.7(7.2-16.3)$ & $9(10 \%)$ & $8.7(5.6-18.1)$ & $4(8 \%)$ & 0.99 \\
\hline
\end{tabular}

$\mathrm{IQR}=$ interquartile range.

* p Value for differences in the proportions of $\%$ abnormal.

$5.2 \mathrm{mmol} / \mathrm{L}, \mathrm{p}<0.001$ ), oliguria ( $48 \%$ vs $65 \%, \mathrm{p}=0.03$ ), higher hsTnT (1,568 ng/L vs 3,592 ng/L, p = 0.004), and lower estimated glomerular filtration rate $\left(66 \mathrm{ml} / \mathrm{min} / 1.73 \mathrm{~m}^{2}\right.$ vs $56 \mathrm{ml} / \mathrm{min} / 1.73 \mathrm{~m}^{2}, \mathrm{p}=0.03$ ) were also associated with abnormal ALT-0h. Compared with survivors, abnormal ALT was more common at all time points in nonsurvivors. In unadjusted Cox regression analysis, abnormal levels of ALT within the first 24 hours were associated with 90-day mortality (ALTOh: HR 1.7, 95\% confidence interval [CI] 1.1 to $2.8, \mathrm{p}=0.03$; ALT-12h: HR 2.3, 95\% CI 1.3 to $4.1, \mathrm{p}=0.003$, and ALT24h: HR 2.3, 95\% CI 1.4 to $5.0, p=0.002$ ). However, the statistical significances were lost after adjustment for variables included in the previously published CardShock score. Abnormal levels of other LFTs within the first 24 hours had no statistically significant associations with 90 -day mortality.

An increase in ALT of $>20 \%$ within 24 hours after baseline $(\triangle \mathrm{ALT}>+20 \%)$ was observed in $24 \%$ of patients (37 of 154). The distribution of ALT changes within 24 hours between survivors and nonsurvivors is available in the Supplementary Material. In Kaplan-Meier analysis (Figure 1), $\Delta$ ALT $>+20 \%$ was associated with a more than 2-fold increase in 90-day mortality compared with those with no significant increase in ALT (ALT stable); $70 \%$ and 28\%, $\mathrm{p}<0.001$. In regression analysis, $\Delta \mathrm{ALT}>+20 \%$ was associated with death within 90 days, with an unadjusted HR of $3.8(95 \%$ CI 2.2 to $6.3, \mathrm{p}<0.001)$. After adjusting for ALT$\mathrm{Oh}$ and the risk factors included in the CardShock risk score, the association remained highly significant (Table 2). The association with mortality was independent of other covariates as well, including further adjustment for the peak hsTnT level within 24 hours and the change in lactate levels from baseline to 24 hours (adjusted HR 3.0, 95\% CI 1.6 to 5.6, $\mathrm{p}=0.001)$.

The increase in ALT within the first 24 hours was an important predictor of 90-day mortality regardless of the absolute baseline level (ALT-Oh) (Figure 2). $\Delta$ ALT $>+20 \%$ was associated with increased mortality both in patients with normal and abnormal ALT-Oh levels. Survival in the ALT stable group

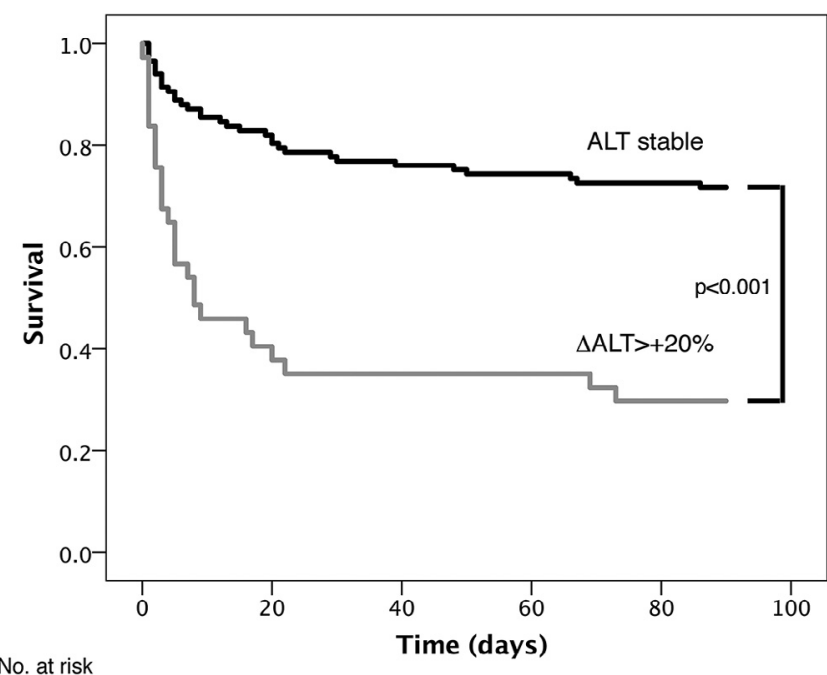

No. at risk

$\begin{array}{llllll}\text { ALT stable } & 119 & 96 & 89 & 87 & 85 \\ \Delta \text { ALT>+20\% } & 37 & 15 & 13 & 13 & 11\end{array}$

Figure 1. Kaplan-Meier survival curves for ALT stable and $\Delta$ ALT $>+20 \%$ ALT stable (black line) $\Delta \mathrm{ALT}>+20 \%$ (gray line). ALT $=$ alanine aminotransferase.

was not significantly different between patients with normal and patients with abnormal ALT-0h. Also, excluding patients who fulfilled the most commonly used criteria for hypoxic hepatitis (ALT $>20$ times the upper limit of normal) did not influence the independent association between $\Delta$ ALT $>+20 \%$ and 90 -day mortality. The observed independent association was not sensitive to variations in the cutoffs used for either $\triangle \mathrm{ALT}$ or abnormal ALT (see Methods section). There were no statistically significant associations between 90-day mortality and increases of $>+20 \%$ of other LFTs within 24 hours of baseline (see Supplementary Material).

Table 3 shows that in patients in CS, $\Delta$ ALT $>+20 \%$ was associated with oliguria and higher levels of lactate as signs 
Table 2

Multivariable Cox regression analysis of factors associated with 90-day mortality

\begin{tabular}{lcc}
\hline Variable & $\begin{array}{c}\text { Hazard ratio } \\
(95 \% \mathrm{CI})\end{array}$ & $\mathrm{p}$ value* \\
\hline Altered mental status & $1.51(0.76-3.01)$ & 0.24 \\
Age (year increment) & $1.04(1.01-1.07)$ & 0.01 \\
Prior myocardial infarction & $1.64(0.85-3.17)$ & 0.14 \\
Prior coronary bypass & $1.83(0.73-4.57)$ & 0.20 \\
Acute coronary syndrome etiology & $1.11(0.48-2.60)$ & 0.81 \\
Left ventricular ejection fraction (\% increment) & $0.98(0.96-1.00)$ & 0.11 \\
Estimated glomerular filtration rate & $1.00(0.99-1.02)$ & 0.83 \\
$\quad$ (mL/min/1.73 m2 increment) & & \\
Lactate at baseline (mmol/L increment) & $1.11(1.04-1.19)$ & 0.002 \\
ALT at baseline (U/L increment) & $1.00(1.00-1.00)$ & 0.75 \\
$\Delta$ ALT $>+20 \%$ & $3.16(1.72-5.82)$ & $<0.001$ \\
\hline
\end{tabular}

ALT $=$ alanine aminotransferase.

* p Value for association with 90-day mortality in the multivariable Cox proportional hazards model.

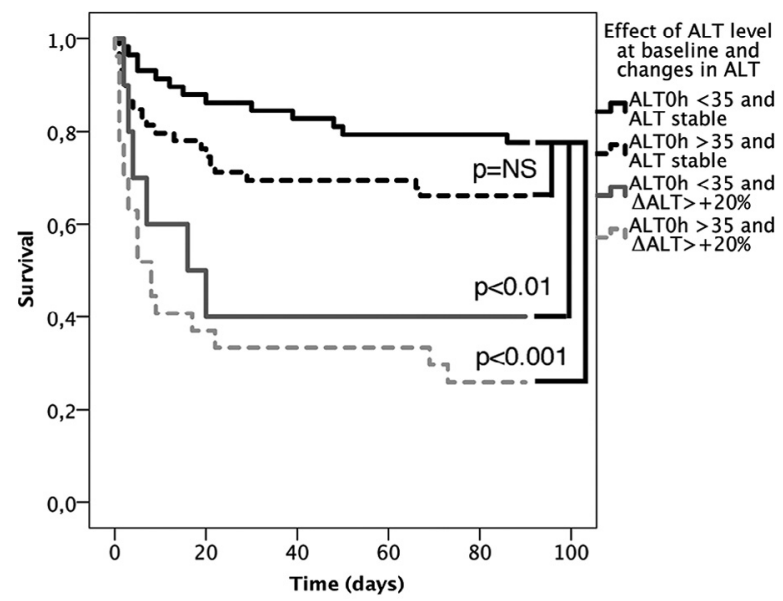

No. at risk

\begin{tabular}{|c|c|c|c|c|}
\hline $\begin{array}{l}\text { ALTOh }<35 \text { and } \\
\text { ALT stable }\end{array}$ & 59 & 51 & 48 & 46 \\
\hline $\begin{array}{l}\text { ALTOh }>35 \text { and } \\
\text { ALT stable }\end{array}$ & 60 & 45 & 41 & 41 \\
\hline $\begin{array}{l}\text { ALTOh }<35 \text { and } \\
\triangle A L T>+20 \%\end{array}$ & 10 & 5 & 4 & 4 \\
\hline $\begin{array}{l}\text { ALTOh }>35 \text { and } \\
\triangle A L T>+20 \%\end{array}$ & 27 & 10 & 9 & 9 \\
\hline
\end{tabular}

Figure 2. Kaplan-Meier survival curves with respect to baseline ALT level and increase in ALT within the first 24 hours. ALT stable group with baseline ALT below (black solid line) or over (black dashed line) the upper limit of normal and $\triangle \mathrm{ALT}>+20 \%$ with baseline ALT below (gray solid line) or over (gray dashed line) the upper limit of normal. ALT $=$ alanine aminotransferase.

of hypoperfusion, as well as lower left ventricular ejection fraction and estimated glomerular filtration rate. There were, however, no significant differences in blood pressure, heart rate, medical history, cardiovascular medications at admission, N-terminal prohormone of B-type natriuretic peptide, or etiology of CS between $\triangle$ ALT $>+20 \%$ and ALT stable groups. A significantly higher peak hsTnT level within 24 hours was observed in the $\Delta$ ALT $>+20 \%$ group.

Serial central venous pressure and cardiac index measurements were available for a total of 79 and 50 patients,
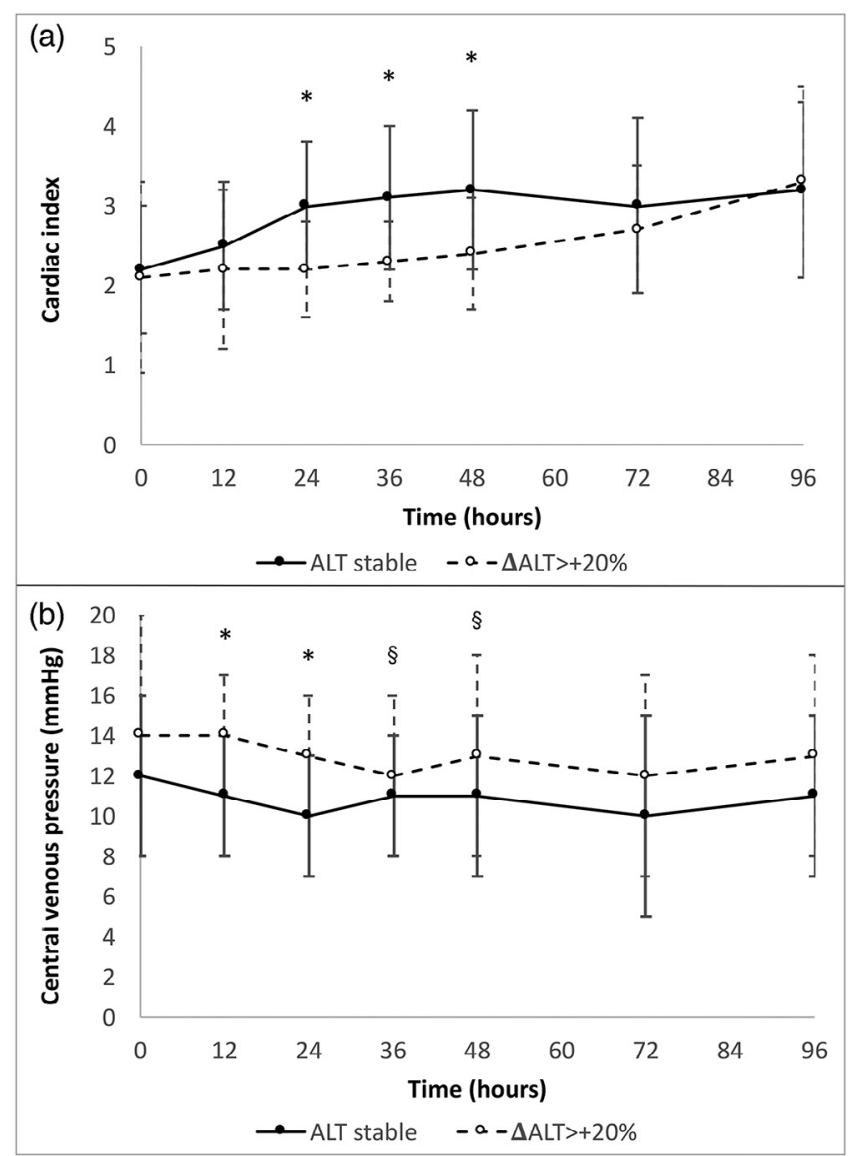

Figure 3. Differences in cardiac index $(A)$ and central venous pressure $(B)$ between ALT stable and $\Delta$ ALT $>+20 \%$ groups. ALT $=$ alanine aminotransferase; $* \mathrm{p}<0.01 ; \S \mathrm{p}<0.10$.

respectively. In the $\Delta \mathrm{ALT}>+20 \%$ group, the cardiac index was initially at the same level, but recovered more slowly and was significantly lower between 24 and 48 hours than ALT stable (Figure 3 ). In the $\Delta$ ALT $>+20 \%$ group, central venous pressure was higher between 12 hours and 24 hours, with a trend toward higher central venous pressure up to 48 hours (Figure 3).

In multivariable logistic regression analysis, left ventricular ejection fraction (OR $0.95,95 \%$ CI 0.92 to $0.99, \mathrm{p}=0.006$ ), mean arterial pressure (OR $0.95,95 \%$ CI 0.90 to 0.99 , $\mathrm{p}=0.03)$, C-reactive protein (OR $0.98,95 \%$ CI 0.97 to 0.99 , $\mathrm{p}=0.01)$, and estimated glomerular filtration rate (OR 0.98 , $95 \%$ CI 0.96 to $0.99, \mathrm{p}=0.002$ ) were found to be independent baseline predictors of $\triangle \mathrm{ALT}>+20 \%$.

\section{Discussion}

This is the first study to investigate the role of early changes in LFTs in association with mortality in CS. The most significant finding is that even modest ( $>20 \%)$ early increases in ALT levels are associated with excess mortality in CS. Although elevated ALT levels were more common in patients who died during follow-up, only an increase in ALT independently predicted mortality. Second, ALT increase was associated with hypoperfusion (higher lactate, oliguria, lower left ventricular ejection fraction, and cardiac index) and higher 
Table 3

Patient characteristics, biochemical findings, and mortality in relation to $>20 \%$ increase in ALT (alanine aminotransferase) within the first 24 hours

\begin{tabular}{|c|c|c|c|c|}
\hline Variable & $\begin{array}{c}\text { All } \\
(\mathrm{n}=154)\end{array}$ & $\begin{array}{l}\text { ALT stable } \\
(\mathrm{n}=117)\end{array}$ & $\begin{array}{c}\Delta \mathrm{ALT}>+20 \% \\
\quad(\mathrm{n}=37)\end{array}$ & $\mathrm{p}$ value \\
\hline \multicolumn{5}{|l|}{ Age (years) } \\
\hline \multicolumn{5}{|l|}{ Body Mass Index $\left(\mathrm{kg} / \mathrm{m}^{2}\right)$} \\
\hline Mean \pm SD & $27(4)$ & $27(4)$ & $27(3)$ & 0.89 \\
\hline Men & $115(75 \%)$ & $89(74 \%)$ & $28(76 \%)$ & 0.99 \\
\hline Resuscitated & $45(29 \%)$ & $32(26 \%)$ & $13(36 \%)$ & 0.30 \\
\hline History of heart failure with reduced ejection fraction & $19(13 \%)$ & $12(10 \%)$ & $7(19 \%)$ & 0.25 \\
\hline Alcohol abuse & $21(13 \%)$ & $20(16 \%)$ & $1(3 \%)$ & 0.05 \\
\hline \multicolumn{5}{|l|}{ Medications at admission } \\
\hline Beta-blockers & $61(40 \%)$ & $47(40 \%)$ & $14(38 \%)$ & 0.85 \\
\hline ACEI/ARB & $65(42 \%)$ & $51(44 \%)$ & $14(38 \%)$ & 0.57 \\
\hline Mean \pm SD & $77(12)$ & $78(11)$ & $75(12)$ & 0.18 \\
\hline \multicolumn{5}{|l|}{ Mean arterial pressure $(\mathrm{mmHg})$} \\
\hline Mean \pm SD & $57(11)$ & $58(10)$ & $55(11)$ & 0.12 \\
\hline \multicolumn{5}{|l|}{ Heart rate (beats/min) } \\
\hline Mean \pm SD & $87(28)$ & $87(27)$ & $85(31)$ & 0.65 \\
\hline \multicolumn{5}{|l|}{ Left ventricular ejection fraction at baseline $(\%)$} \\
\hline Mean \pm SD & $33(13)$ & $35(14)$ & $28(11)$ & 0.01 \\
\hline Acute coronary syndrome etiology & $124(79 \%)$ & $91(76 \%)$ & $33(89 \%)$ & 0.11 \\
\hline Oliguria & $80(53 \%)$ & $55(48 \%)$ & $25(69 \%)$ & 0.04 \\
\hline Altered mental status at presentation & $103(66 \%)$ & $76(64 \%)$ & $27(73 \%)$ & 0.42 \\
\hline \multicolumn{5}{|l|}{ Biochemical findings } \\
\hline \multicolumn{5}{|l|}{ NT-proBNP at baseline (ng/L) } \\
\hline \multicolumn{5}{|l|}{ ALT at 12 hours (U/L) } \\
\hline Median (IQR) & $44(17-108)$ & $33(15-63)$ & $153(73-337)$ & $<0.001$ \\
\hline \multicolumn{5}{|l|}{ ALT at 24 hours $(\mathrm{U} / \mathrm{L})$} \\
\hline Median (IQR) & $37(18-85)$ & $27(14-58)$ & $109(62-489)$ & $<0.001$ \\
\hline \multicolumn{5}{|l|}{ ALT change within 24 hours (U/L) } \\
\hline Median (IQR) & $-1(-16-16)$ & $-8(-25-3)$ & $69(29-329)$ & \\
\hline \multicolumn{5}{|l|}{ ALT change within 24 hours $(\%)$} \\
\hline Median (IQR) & $-5(-32-47)$ & $-18(-41-7)$ & $101(49-529)$ & \\
\hline \multicolumn{5}{|l|}{ Lactate at baseline $(\mathrm{mmol} / \mathrm{L})$} \\
\hline Median (IQR) & $2.5(1.6-5.1)$ & $2.4(1.5-3.6)$ & $5.0(2.4-7.3)$ & $<0.001$ \\
\hline Lactate at 12 hours & & & & \\
\hline Median (IQR) & $1.6(1.1-2.7)$ & $1.4(1.0-2.6)$ & $2.3(1.5-5.0)$ & 0.004 \\
\hline Lactate at 24 hours & & & & \\
\hline $\begin{array}{l}\text { Median (IQR) } \\
\text { estimated glomerular filtration rate; } \mathrm{mL} / \mathrm{min} / 1.73 \mathrm{~m}^{2}\end{array}$ & $1.3(1.0-1.9)$ & $1.2(0.9-1.8)$ & $1.6(1.2-3.6)$ & 0.001 \\
\hline Mean \pm SD & $65(28)$ & $68(28)$ & $56(25)$ & 0.02 \\
\hline 90-day mortality & $59(38 \%)$ & $33(28 \%)$ & $26(70 \%)$ & $<0.001$ \\
\hline
\end{tabular}

Results shown as \% for categorical, and mean (SD) or median (IQR) for continuous variables.

$\mathrm{ACEI}=$ angiotensin-converting enzyme inhibitor; $\mathrm{ALT}=$ alanine aminotransferase $\mathrm{ARB}=$ angiotensin receptor blocker; hsTnT $=$ high-sensitivity troponin $\mathrm{T}$; IQR = interquartile range; NT-proBNP $=\mathrm{N}$-terminal prohormone of B-type natriuretic peptide. 
central venous pressure. Finally, baseline levels or early increases of other LFTs investigated (alkaline phosphatase, GGT, bilirubin) showed no statistically significant association with 90-day mortality.

Abnormal ALT levels at baseline were associated with higher mortality, but this association was lost when other variables previously shown to be independently associated with mortality in CS were included in the multivariable model. This is in line with previous findings, suggesting that ALT can be used as a surrogate marker for hemodynamics in acute heart failure, but is not independently associated with mortality. ${ }^{9}$ By contrast, in our study, increase of ALT by $>20 \%$ within 24 hours was independently associated with poor survival, even after adjustment for the considerably higher lactate levels in the $\Delta \mathrm{ALT}>+20 \%$ group. Moreover, the effect of early ALT increase on mortality was strong regardless of baseline ALT. Baseline ALT can be elevated because of preexisting conditions (in fact, there were more patients with history of alcohol abuse in the ALT stable group). Therefore, early increases in ALT may be a more reliable indicator of hypoperfusion caused by CS. Indeed, central venous pressures and cardiac index differed between ALT stable and $\Delta$ ALT $>+20 \%$ groups. It seems that a stable and/or resolving ALT may reflect rapid reversal of the hypoperfusion state, whereas an increase in ALT suggests prolonged and more severe hemodynamic derangements.

In our study, independent baseline predictors of $\Delta$ ALT $>+20 \%$ were low left ventricular ejection fraction, low mean arterial pressure, low C-reactive protein, and low estimated glomerular filtration rate at baseline. Low left ventricular ejection fraction and low mean arterial pressure can lead to hypoperfusion-induced liver injury, causing an increase in ALT. Conversely, early liver dysfunction caused by hypoperfusion can lead to a decrease in the production of C-reactive protein in the liver. In a study of hypoxic hepatitis in cardiogenic shock, admission serum creatinine (from which estimated glomerular filtration rate is derived) was a predictor of hypoxic hepatitis in univariable analysis. ${ }^{16}$ In addition to preexisting renal dysfunction, acute kidney injury and liver dysfunction may have similar causes in CS, as there were more patients who also developed acute kidney injury in the $\Delta$ ALT $>+20 \%$ group (Table 3 ).

There was a significant association between $\Delta \mathrm{ALT}>+20 \%$ and peak hsTnT level within 24 hours. It is possible that some of the increase in ALT was cardiac in origin, as cardiac muscle has been shown to contain small amounts of ALT. ${ }^{19}$ More likely, the observed association could be due to larger acute myocardial infarctions causing a more profound deterioration in cardiac output (as shown by the lower cardiac index in the $\Delta \mathrm{ALT}>+20 \%$ group), resulting in liver hypoperfusion and ALT release of hepatic origin. Nonetheless, even after adjusting for the association with peak hsTnT level within 24 hours, $\Delta$ ALT $>+20 \%$ was independently associated with 90-day mortality. This is in accordance with a previous study in the critically ill, where the degree of hepatic impairment (illustrated by prothrombin time) was an independent predictor of mortality in patients with hypoxic hepatitis. ${ }^{14}$ Previous investigations on the effect of transaminase elevations (ALT, aspartate aminotransferase) in critically ill patients have focused on more marked increases. A recent meta-analysis of 24 studies on hypoxic hepatitis ${ }^{20}$ reported that the cut-off level of trans- aminase elevations for the diagnosis of hypoxic hepatitis varied in investigations between $>300$ and $>3,000$. Elevations of that magnitude were rare in this cohort of CS. Modest increases, such as those observed in the present study, have previously been described to affect survival in acute heart failure ${ }^{5}$ and in patients with acute ST-elevation myocardial infarction, ${ }^{21}$ and even low values within the normal range have been previously shown to be associated with decreased survival in heart failure. $^{22}$

In the present study, abnormal values of bilirubin or GGT showed no association with mortality. This is in contrast to studies in acute heart failure, where it has been shown that $\mathrm{GGT}^{8,23}$ and total bilirubin ${ }^{7}$ are markers of poor prognosis. Previous investigations ${ }^{9,24,25}$ have also shown a link in heart failure between LFTs and central venous pressure, as well as cardiac index. We found an association between cardiac index and ALT, as well as central venous pressure and ALT, but not with total bilirubin, alkaline phosphatase, or GGT. The observed differences could be owing to the timing of the samples in relation to the nascent liver injury and differences in study populations. Most of the previous studies ${ }^{3-5,7}$ have excluded patients in CS and patients with acute coronary syndrome, so the results are not representative for CS, where the majority is caused by myocardial infarction. As shown by Jäger et al, ${ }^{26}$ the laboratory pattern of jaundice and cholestasis frequently occurs several days following acute hepatic injury, whereas transaminases, such as ALT, have been shown to increase rapidly in case of hypoxic shock due to liver cell necrosis. ${ }^{27}$ Consequently and in accordance with our data, alkaline phosphatase, GGT, and bilirubin seem not to be appropriate tools for early risk stratification in patients in CS.

Our study has several limitations. First, not all patients with values at baseline could be included in the analyses on early changes of LFTs. Some patients died already during the first 24 hours, and a few more were excluded because of missing samples. Nevertheless, considering the general challenges with serial sampling in acute cardiac care, the final cohort available for analysis of changes in LFTs is, to our knowledge, unique. Second, hemodynamic measurements were available only from a proportion of patients. The use of pulmonary artery catheter and central venous pressure measurements was at the discretion of the treating physician. Invasive hemodynamic monitoring is not routinely advocated, and we believe that our cohort reflects current clinical practice. Third, the cutoff of $20 \%$ change for ALT was extrapolated from data in acute heart failure, and needs to be confirmed by other studies. Sensitivity analyses in our cohort suggested the selected value to be clinically relevant. Finally, CS is a complex syndrome, and although adjustment for all relevant available variables was performed in mortality analyses, unaccounted differences in the treatment between survivors and nonsurvivors may remain.

In conclusion, the present study describes the prevalence and clinical importance of LFT abnormalities in CS. Although ALT levels are frequently elevated at baseline, only an increase in ALT by $20 \%$ or more within the first 24 hours was strongly and independently associated with higher 90day mortality. The study suggests that early increases in ALT in patients in CS are related to organ hypoperfusion, as evidenced by lower cardiac index and other clinical markers of hypoperfusion. Based on these results, we suggest that serial 
ALT measurements should be incorporated in the clinical assessment of patients in CS.

\section{The CardShock Steering Committee}

Veli-Pekka Harjola (chair), Marek Banaszewski, Lars Køber, Johan Lassus, Alexandre Mebazaa, Marco Metra, John Parissis, Jose Silva-Cardoso, Alessandro Sionis, Salvatore Di Somma, and Jindrich Spinar. List of investigators: Athens: Katerina Koniari, Astrinos Voumvourakis, Apostolos Karavidas; Barcelona: Jordi Sans-Rosello, Montserrat Vila, Albert Duran-Cambra; Brescia: Marco Metra, Michela Bulgari, Valentina Lazzarini; Brno: Jiri Parenica, Roman Stipal, Ondrej Ludka, Marie Palsuva, Eva Ganovska, Petr Kubena; Copenhagen: Matias G. Lindholm, Christian Hassager; Helsinki: Tom Bäcklund, Raija Jurkko, Kristiina Järvinen, Tuomo Nieminen, Kari Pulkki, Leena Soininen, Reijo Sund, Ilkka Tierala, Jukka Tolonen, Marjut Varpula, Tuomas Korva, Anne Pitkälä; Rome: Rossella Marino; Porto: Alexandra Sousa, Carla Sousa, Mariana Paiva, Inês Rangel, Rui Almeida, Teresa Pinho, Maria Júlia Maciel; Warsaw: Janina Stepinska, Anna Skrobisz, Piotr Góral. The study was performed in collaboration with the Global Research on Acute Conditions network.

\section{Disclosures}

Dr. Lassus has served on an advisory board for BoehringerIngelheim, Medix Biochemica, Novartis, Servier, and Vifor Pharma and received lecture fees from Bayer, BoehringerIngelheim, Pfizer, Novartis, Orion Pharma, and Vifor Pharma. Dr. Sionis has served on an advisory board for Orion Pharma, and received lecture fees from Astra-Zeneca, Bayer, Menarini, Novartis, and Servier. Dr. Parissis has received honoraria from Novartis and Orion Pharma. Dr. SilvaCardoso has consulted and received speaker fees, or investigational grants from Abbott, AstraZeneca Pharmaceuticals, Menarini, Merck Serono, Merck Sharp \& Dohme, Novartis, Orion, Pfizer, Sanofi, and Vifor. No other disclosures were reported.

\section{Supplementary Data}

Supplementary data related with this article can be found, in the online version, at http://dx.doi.org/10.1016/ j.amjcard.2017.06.049.

1. Allen LA, Felker GM, Pocock S, McMurray JJV, Pfeffer MA, Swedberg K, Wang D, Yusuf S, Michelson EL, Granger CB. for the CHARM Investigators. Liver function abnormalities and outcome in patients with chronic heart failure: data from the Candesartan in Heart Failure: Assessment of Reduction in Mortality and Morbidity (CHARM) program. Eur J Heart Fail 2009;11:170-177.

2. Møller S, Bernardi M. Interactions of the heart and the liver. Eur Heart $J$ 2013;34:2804-2811

3. van Deursen VM, Edwards C, Cotter G, Davison BA, Damman K, Teerlink JR, Metra M, Felker MG, Ponikowski P, Unemori E, Severin T, Voors AA. Liver function, in-hospital, and post-discharge clinical outcome in patients with acute heart failure-results from the relaxin for the treatment of patients with acute heart failure study. J Card Fail 2014:20:407-413.

4. Nikolaou M, Parissis J, Yilmaz MB, Seronde MF, Kivikko M, Laribi S, Paugam-Burtz C, Cai D, Pohjanjousi P, Laterre PF, Deye N, Poder $\mathrm{P}$, Cohen-Solal A, Mebazaa A. Liver function abnormalities, clinical profile, and outcome in acute decompensated heart failure. Eur Heart J 2013;34:742-749.
5. Metra M, Cotter G, Davison BA, Felker GM, Filippatos G, Greenberg BH, Ponikowski P, Unemori E, Voors AA, Adams KF, Donobantu MI, Grinfeld L, Jondeau G, Marmor A, Masip J, Pang PS, Werdan K, Prescott MF, Edwards C, Teichman SL, Trapani A, Bush CA, Saini R, Schumacher C, Severin T, Teerlink JR. Effect of serelaxin on cardiac, renal, and hepatic biomarkers in the relaxin in acute heart failure (RELAXAHF) development program. J Am Coll Cardiol 2013;61:196-206.

6. Biegus J, Hillege HL, Postmus D, Valente MAE, Bloomfield DM, Cleland JGF, Cotter G, Davison BA, Dittrich HC, Fiuzat M, Givertz MM, Massie BM, Metra M, Teerlink JR, Voors AA, O'Connor CM, Ponikowski P. Abnormal liver function tests in acute heart failure: relationship with clinical characteristics and outcome in the PROTECT study. Eur J Heart Fail 2016;18:830-839.

7. Ambrosy AP, Vaduganathan M, Huffman MD, Khan S, Kwasny MJ, Fought AJ, Maggioni AP, Swedberg K, Konstam MA, Zannad F, Gheorghiade M. on behalf of the EVEREST trial investigators. Clinical course and predictive value of liver function tests in patients hospitalized for worsening heart failure with reduced ejection fraction: an analysis of the EVEREST trial. Eur J Heart Fail 2014;14:302311.

8. Parissis JT, Farmakis D, Andreoli C, Rafouli-Stergiou P, Ambrosio G, Anastasiou-Nana M, Filippatos G. Cardio-reno-hepatic interactions in acute heart failure: the role of $\gamma$-glutamyl transferase. Int $J$ Cardiol 2014;173:556-557.

9. van Deursen VM, Damman K, Hillege HL, van Beek AP, van Veldhuisen DJ, Voors AA. Abnormal liver function in relation to hemodynamic profile in heart failure patients. J Card Fail 2010;16:84-90.

10. Vyskocilova K, Spinarova L, Spinar J, Mikusova T, Vitovec J, Malek J, Malek F, Linhart A, Fedorco M, Widimsky P, Cihalik C, Parenica J, Littnerova S, Jarkovsky J. Prevalence and clinical significance of liver function abnormalities in patients with acute heart failure. Biomed Pap Med Fac Univ Palacky Olomouc Czech Repub 2015;159:429436.

11. Topalian S, Ginsberg F, Parrillo JE. Cardiogenic shock. Crit Care Med 2008:36:S66-S74.

12. Hochman JS. Cardiogenic shock complicating acute myocardial infarction: expanding the paradigm. Circulation 2003;107:2998-3002.

13. Kramer L, Jordan B, Druml W, Bauer P, Metnitz PGH, Austrian Epidemiologic Study on Intensive Care, ASDI Study Group. Incidence and prognosis of early hepatic dysfunction in critically ill patients-a prospective multicenter study. Crit Care Med 2007;35:1099-1104.

14. Fuhrmann V, Kneidinger N, Herkner H, Heinz G, Nikfardjam M, Bojic A, Schellongowski P, Angermayr B, Kitzberger R, Warszawska J, Holzinger U, Schenk P, Madl C. Hypoxic hepatitis: underlying conditions and risk factors for mortality in critically ill patients. Intensive Care Med 2009;35:1397-1405.

15. Whitehead MW, Hawkes ND, Hainsworth I, Kingham JG. A prospective study of the causes of notably raised aspartate aminotransferase of liver origin. Gut 1999;45:129-133.

16. Jung C, Fuernau G, Eitel I, Desch S, Schuler G, Kelm M, Adams V, Thiele $\mathrm{H}$. Incidence, laboratory detection and prognostic relevance of hypoxic hepatitis in cardiogenic shock. Clin Res Cardiol 2016;1-9.

17. Harjola V-P, Lassus J, Sionis A, Køber L, Tarvasmäki T, Spinar J, Parissis J, Banaszewski M, Silva-Cardoso J, Carubelli V, Di Somma S, Tolppanen $\mathrm{H}$, Zeymer U, Thiele H, Nieminen MS, Mebazaa A. for the CardShock study investigators and the GREAT network. Clinical picture and risk prediction of short-term mortality in cardiogenic shock. Eur J Heart Fail 2015;17:501-509.

18. Levey AS, Stevens LA, Schmid CH, Zhang YL, Castro AF, Feldman HI, Kusek JW, Eggers P, Van Lente F, Greene T, Coresh J, CKD-EPI (Chronic Kidney Disease Epidemiology Collaboration). A new equation to estimate glomerular filtration rate. Ann Intern Med 2009;150:604 612.

19. Lindblom P, Rafter I, Copley C, Andersson U, Hedberg JJ, Berg A-L, Samuelsson A, Hellmold H, Cotgreave I, Glinghammar B. Isoforms of alanine aminotransferases in human tissues and serum-differential tissue expression using novel antibodies. Arch Biochem Biophys 2007;466:6677.

20. Tapper EB, Sengupta N, Bonder A. The incidence and outcomes of ischemic hepatitis: a systematic review with meta-analysis. Am J Med 2015;18.

21. Moon J, Kang W, Oh PC, Seo SY, Lee K, Han SH, Ahn T, Shin E. Serum transaminase determined in the emergency room predicts outcomes in patients with acute ST-segment elevation myocardial infarction 
who undergo primary percutaneous coronary intervention. Int J Cardiol 2014;177:442-447.

22. Ambrosy AP, Dunn TP, Heidenreich PA. Effect of minor liver function test abnormalities and values within the normal range on survival in heart failure. Am J Cardiol 2015;115:938-941.

23. Turfan M, Tasal A, Erdogan E, Vatankulu MA, Jafarov P, Sonmez O, Ertas G, Bacaksız A, Ergelen M, Goktekın O. Serum gamma-glutamyl transferase levels and in-hospital mortality in patients with acute heart failure. Kardiol Pol 2014;72:735-739.

24. Shinagawa $H$, Inomata $T$, Koitabashi $T$, Nakano $H$, Takeuchi I, Naruke T, Ohsaka T, Nishii M, Takehana H, Izumi T. Prognostic significance of increased serum bilirubin levels coincident with cardiac decompensation in chronic heart failure. Circ J 2008;72:364 369.

25. Kubo SH, Walter BA, John DH, Clark M, Cody RJ. Liver function abnormalities in chronic heart failure. Influence of systemic hemodynamics. Arch Intern Med 1987;147:1227-1230.

26. Jäger B, Drolz A, Michl B, Schellongowski P, Bojic A, Nikfardjam M, Zauner C, Heinz G, Trauner M, Fuhrmann V. Jaundice increases the rate of complications and one-year mortality in patients with hypoxic hepatitis. Hepatology 2012;56:2297-2304.

27. Henrion J, Schapira M, Luwaert R, Colin L, Delannoy A, Heller FR. Hypoxic hepatitis: clinical and hemodynamic study in 142 consecutive cases. Medicine (Baltimore) 2003;82:392-406. 